\title{
NEW INSTALLATIONS FOR B.B.C. TELEVISION
}

$\mathrm{S}^{\mathrm{n}}$ INCE June 1955 a series of Engineering Monographs* has been published by the B.B.C., dealing with technical subjects within the field of television and sound broadcasting. Each Monograph describes work carried out by the Engineering Division of the Corporation and includes, where appropriate, a survey of earlier work on the seme subject. About six Monographs are produced each year.

Monograph No. 12 is entitled "An Improved 'Roving Eye',", by T. Worswick and G. W. H. Larkby, and it describes the new design of mobile television camera which, with its associated equipment and short-range radio-link transmitter, permits pictures and their sound accompeniment to be broadcast while the vehicle is in motion and unimpeded by any connecting cables. The vehicle is equipped with two cameras, one of which gets a direct view forward through the windscreen or at right-angles to take kerbside interview shots. The second camera is mounted on a machine-gun ring and can be elevated with its operator to a position well clear of the roof. With this arrangement the camera can be swung to look all around the vehicle; and it can also be tilted on the mounting to take steep downward shots, for example to look on the pavement or in shop windows. The sound and vision signals are transmitted to the broadcasting network by a radio link on a frequency of about $660 \mathrm{Mc} / \mathrm{s}$. When the vehicle is 'roving', a short aerial a few feet high is used to enable the van to pass under bridges ; and in this case the maximum distance from the receiving base is some two or three miles. The vehicle is, how ever, also provided with a $45 \mathrm{ft}$. pneumatically operated telescopic mast, which can be used from a fixed position to send the signals over a distance of ten to

- Obtainable from B.B.C. Publications, 35 Marylebone High Street, London, W.1. 5s. each, 20s, per year. fifteen miles from the receiving base. The normal crew of the vehicle comprises a driver, two cameramen, two operators, a commentator and producer; and the equipment is complete with an engine-driven alternator for the power required by the camerss, control units and the radio transmitter.

The two succeeding Monographs describe the premises at Hammersmith which the B.B.C. has recently converted into a self-contained television studio centre. No. 13 is entitled: "The B.B.C. Riverside Television Studios: The Architectural Aspects", by E. A. Fowler. It describes in some detail, with appropriate drawings and photographs, the planning and construction of the two studios, occupying 6,000 and 4,200 sq. ft., respectively, together with all the necessary equipment and facilities for the staging and production of television programmes. The incorporation of many new features on the engineering side, particularly in the fields of lighting control and co-ordination of the production and engineering staffs, has been made possible by the careful planning and layout of the studios and their auxiliary areas.

The technical accommodation and equipment are described in more detail in Monograph No. 14, entitled: "The B.B.C. Riverside Television Studios : Some Aspects of Technical Planning and Equipment", by H. C. Nickels and D. M. B. Grubb. As in the former case this number is well illustrated with plans, diagrams, photographs showing the studios, control rooms and assooiated lighting, camers and telecine equipment. The Riverside Studios represent the latest and most modern practice in the equipment of television studios in Britain: while they include certain novel features, they are essentially the outcome of experience gained over a considerable number of years.

\section{THE PHYSICAL SOCIETY DURING 1957}

$\mathrm{T}$ HE 1957 Year Book of the Physical Society (pp. iv +132. London: The Physical Society, 1957. 12s. $6 d$.) is the third in the annual series and contains the report of the Council of the Society for 1956; the proceedings of the meetings of the Society; obituary notices of five fellows, including Sir Francis Simon and Sir John Townsend; and the texts of the presidential address and of the special lectures and discourses delivered to the Society during the year.

The presidential address, entitled "The Physics and Chemistry of Metals", was delivered by Prof. N. F. Mott on June 4, following the annual general meeting of the Society (see Nature, 180, 272; 1957). The forty-first Guthrie Lecture, given by Prof. H. C. Urey on April 9 during the spring meeting of the Society at the University of Nottingham, was originally entitled "Some Chemical Limitations on Theories for the Origin of the Solar System". However, Prof. Urey has since been able to study the interesting observations of E. K. Gerling and L. K. Levskii made in 1956 in the U.S.S.R. and he has consequently modified and added many points and details to his lecture, with the result that the revised text appears under the title "Meteorites and the Origin of the Solar System". Prof. Urey points out that though meteorites have been investigated by chemists and mineralogists for more then a century, since the Second World War new and modern techniques have been applied to the problem, and he proceeds to review both the older and more recent data, and to outline possible series of events which may have led to the formation of meteorites. Recent work on radioactive dating methods, it is stated, shows conclusively that a most involved series of chemical and physical processes took place some 4.5 seons ago (an aeon is $10^{9}$ years) during the period in which the solar system originated.

In the nineteenth Thomas Young Oration which he delivered on Mry 15, Dr. J. Guild, of the Nationsl Physical Laboratory, describes observations on the behaviour of diffraction gratings, dealing particularly with those properties which affect image formation. Following a description of the test-bench employed at the Laboratory for the examination of the gratings, a number of examples are given of the peculiarities of behaviour of typical diffraction gratings of various origins as revealed by the tests. The examples show 
that the best gratings, regarded as optical instruments, are of poor quality by the standards normally applied to plane or concave reflectors, thus leaving considerable room for improvement in the technique of their production.

The magnetic refrigerator for temperatures below $1^{\circ} \mathrm{K}$. was the subject of the thirty-third Duddell Medal address given by Prof. J. G. Daunt. A shortened version of the address (for the full text see Proc. Phys. Soc., B, 70, 641; 1957) is included in the Year Book, together with the thirty-fourth Duddell Medal address on the scale-of-two counter by Dr. C. E. Wynn-Williams; the twelfth Charles Vernon Boys Prize address on "Hyperons and $K$-mesons: a Survey of the Results of the First Decade" by Prof. G. D. Rochester and Dr. C. C. Butler; the thirteenth Charles Vernon Boys Prize address by Dr. L. Essen on the measurement of the velocity of light; and the three evening discourses delivered at the fortyfirst Physical Society exhibition of scientific instruments and apparatus during March 25-28.

S. WeINTROUB

\title{
PUBLIC HEALTH TRAINING OF GENERAL PRACTITIONERS
}

TN many countries, general practitioners are re1 quired, in addition to their private practice, to devote part of their time to public health activities. They are thus called upon to play an important part in the protection of public health-a role for which they have not always received adequate training. A conference* to discuss this problem was organized by the World Health Organization in October and ovember 1956.

N'The main tasks of the conference were to examine the reasons for the frequent indifference of general practitioners to public health questions, to seek a means of arousing their interest in them, and to establish certain general principles for the guidance of those responsible for the organization of the public health training of general practitioners.

It was agreed that the first cause of indifference is in the present university and post-university curricula, which lay the main emphasis on diagnostic and therapeutic aspects. This is a gap which has to be bridged if the general practitioner is to be able to fulfil his public health role efficiently. Another reason for the lack of interest is that the young medical graduate finds the prestige and material compensations of private practice more attractive than public health work.

If the general practitioner's interest in public health work is to be aroused, the health authorities have to keep him informed of their plans for col-

* World Health Organization. Technical Report Series, No. 140. Stationery Office, 1957.) 1 Swiss frane; 18. $9 d$.; 0.30 dollars. lective activities, and-whenever possible-invite his participation. For his part, the practitioner should realize that, even from the point of view of individual therapeutic care, there are advantages in having a modern public health service at his disposal.

There are various ways of maintaining effective liaison between the health administration and general practitioners, including periodic health bulletins, personal contacts and organization of meetings. Courses and seminars in which general practitioners are invited to participate are particularly helpful, and in several countries excellent results have been obtained by international teaching teams which have organized lectures and discussions in hospital centres on public health.

The report examines in detail the organization of courses for part-time public health medical officers and the various related problems, including time and place of courses, selection of teachers, content and arrangement of syllabuses. If physicians are to become familiar with the nature and aims of public health activities, if they are to take as much interest in these as in other aspects of their profession, and if they are to acquire the necessary technical competence, training programmes should cover, among others, the following subjects : role of the physician in society; role of the publie health administration; reciprocal collaboration; epidemiological methods; environmental senitation; importance of external services (social services); and the interrelationship of curative and preventive medicine.

\section{SENSORY DEPRIVATION AND THE CAT'S OPTIC NERVOUS SYSTEM}

\author{
BY DR. LAWRENCE WEISKRANTZ \\ Psychological Laboratory, Uiiversity of Cambridge
}

\begin{abstract}
$\mathrm{T}$ HAT rearing in darkness of rabbits ${ }^{1}$, $\operatorname{cats}^{2}$ and chimpanzees ${ }^{3}$ can produce severe behavioural impairment in visual tasks is now well established. Less certain is whether this impairment can be attributed to peripheral neural changes, to the lack of opportunity to learn how to see-reflected, presumably, in neural changes limited to more central loci-or to both these factors.

The present investigation was undertaken to examine carefully the visual system of cats reared in darkness. The rearing was intentionally designed to conform to the schedule of an earlier study by Riesen,
\end{abstract}

Kurke and Mellinger ${ }^{2}$. The five experimental animals were put into a dark room from the age of 7 days (before their eyes were opened) until they were 17 weeks old. From their fourteenth to seventeenth weeks, they were given a daily $\frac{1}{2}-\mathrm{hr}$. run in a normally illuminated room. During this period, the left eye of each animal received only diffuse illumination. This was achieved by fitting the animal with a mask with a semi-translucent insert in front of the left eye. The right eye received normal unobstructed stimulation. Riesen, Kurke and Mellinger found that cats reared in this manner not only had difficulty in 